\title{
Stigmatization and self-perception of youth with attention deficit/hyperactivity disorder
}

This article was published in the following Dove Press journal:

Patient Intelligence

5 June 2013

Number of times this article has been viewed

\section{Regina Bussing \\ Anuja S Mehta}

Department of Psychiatry, University of Florida, Gainesville, FL, USA
Correspondence: Regina Bussing Health Science Center, Department of Psychiatry, University of Florida, Room HD-G-20, 1600 SW Archer Road, Gainesville, FL 2610-0234, USA Tel +l 3522737550

Fax + I 352846 I455

Email rbussing@ufl.edu
Abstract: Increasing numbers of families must learn to manage their child's attention deficit/ hyperactivity disorder (ADHD) through multimodal interventions that may include psychosocial, educational, and medication treatments. Like others with mental disorders, youth with ADHD face significant stigma in its various forms, including public (expressed as prejudice and discrimination), courtesy (stigma suffered by family members or associates of individuals with ADHD), and self-stigma (stigmatized individual's acceptance of negative views by others). Successful ADHD management requires awareness of stigma and of its potential adverse consequences on treatment initiation and persistence, but also calls for effective means to combat it. This review on stigmatization and self-perception of youth with ADHD first considers the current context of management and treatment options. Next, we appraise recent research in ADHD stigma measurement, identifying a dearth of validated tools and a need for additional instrument development, especially brief measures suitable for clinical encounters. The review then addresses studies of public stigma from the perspectives of youth and adults. A number of qualitative studies document the ubiquitous nature of public stigma experiences associated with ADHD from the perspectives of caregivers. Notably, impressions gathered in qualitative research are confirmed through quantitative studies of representative youth and adult samples, such as the National Stigma Study - Children, which report considerable stigmatization of ADHD by the general public. Unlike public stigma, courtesy stigma has not been examined through large-scale quantitative studies. However, courtesy stigma has been amply documented in qualitative research as a phenomenon experienced at various ecological levels, within the dyadic relationship with the affected child to interactions with immediate and extended family, community, and health and educational systems. Very limited research could be identified for self-stigma of youth affected by ADHD, with reports of lowered self-esteem in response to public stigma. General societal antistigma programs have been developed and implemented, consisting of three paradigms - protest, education, and contact - but insufficient guidance exists for ADHD treatment providers on how to combat stigma experienced by individual patients with ADHD and their families.

Keywords: attention deficit/hyperactivity disorder, stigma, public stigma, courtesy stigma, self-stigma, treatment barriers

\section{Management issues in attention deficit/ hyperactivity disorder}

Attention deficit/hyperactivity disorder (ADHD) is a common neurodevelopmental disorder with childhood onset, characterized by severe and pervasive patterns of inattention, hyperactivity, and impulsivity in more than one setting, and associated with significant functional impairment. ${ }^{1}$ Increasing numbers of families must learn to manage their child's $\mathrm{ADHD}$, because this disorder is among the most commonly diagnosed neurobehavioral 
disorders and the number of affected youth is rising. According to the Centers for Disease Control and Prevention, parentreported ADHD prevalence increased by $21.8 \%$ between 2003 and 2007 , now affecting $9.5 \%$ of US children. ${ }^{2}$ An important aspect of disease management is handling the stigma associated with $\mathrm{ADHD}$, in particular notions that the disorder is the result of inadequate parenting or willful child misbehavior. ${ }^{3}$ Attributions of ADHD to faulty upbringing are common, even though the neurobiological causation of ADHD is supported by results of genetic, neuropsychological, and neuroimaging studies. $^{4-7}$ ADHD symptoms frequently start in early childhood and continue for many years; a recent international study reported that half of the cases of childhood ADHD persist into adulthood. ${ }^{8}$ This means that families have to adopt long-term management strategies, not just time-limited ones like for an acute infectious illness. To complicate the management demands, ADHD is frequently accompanied by other disorders, including disruptive, mood, anxiety, and substance-use disorders, resulting in significant functional impairment at home, in school, and with peers. ${ }^{9}$ Thus, it is not surprising that ADHD negatively impacts youth quality of life similar to severe physical disorders, particularly from the perspective of parents. ${ }^{10}$ Unfortunately, parents frequently encounter higher financial barriers for ADHD treatment than for physical disorders, because of inadequate mental health insurance coverage for doctor visits and/or medications. ${ }^{11}$ Furthermore, due to its genetic underpinnings, ADHD frequently affects more than one family member. Having multiple children with ADHD increases parental management demands considerably. If parents suffer from ADHD themselves, they frequently require their own treatment in order to manage successfully the multiple demands of family life with ADHD. ${ }^{12}$ Thus, successful parental management of ADHD requires (1) comprehensive ADHD knowledge, (2) communication skills for interactions with the affected child, health professionals, insurance agents, teachers, and social network members, (3) knowledge about treatment options and their desirable and undesirable side effects, (4) ability to set specific treatment goals, and (5) skills to access relevant social support, for example through support groups like Children and Adults with Attention Deficit/Hyperactivity Disorder (www.chadd.org) or the National Alliance on Mental Illness (www.nami.org) as a means to connect with other families who cope with child mental health issues.

\section{Current treatment options for ADHD}

Current treatment guidelines specify that ADHD interventions for children and adolescents should be multimodal and include (1) age- and culture-appropriate ADHD psychoeducation for caregivers and youth, (2) treatment plans consisting of medications and/or behavior therapy, (3) educational recommendations addressing topics such as Section 504 plans to improve school performance, and (4) targeted family support. ${ }^{13-16}$ Caregivers and youth need to be active partners in treatment-plan development. ${ }^{17}$ Of the psychosocial treatments, behavioral parent training, behavioral classroom management, and peer-focused behavior interventions in recreational settings (like summer camps) have well-established efficacy; however, the latter are frequently unavailable in usual community settings. ${ }^{15}$ Other types of psychotherapy, alone and in combination with medications, may be indicated for patients with ADHD and comorbid disorders, eg, habit-reversal training for tic disorders, ${ }^{18}$ multisystemic family therapy for disruptive behavior disorders, ${ }^{19}$ or cognitive behavior therapy for obsessive-compulsive disorders. ${ }^{20} \mathrm{~A}$ recent systematic review and meta-analysis of nonpharmacological interventions, including dietary, behavioral, cognitive, and neurofeedback modalities, found small but significant symptom reductions produced by free fatty acid supplementation, but cautioned that better evidence from blinded assessment is needed before nonpharmacological interventions can be supported as treatments for core ADHD symptoms. ${ }^{21}$

Pharmacotherapy plays a fundamental role in ADHD treatment of children and adolescents. ${ }^{13,16}$ Medications approved by the Food and Drug Administration for ADHD include short- and long-acting stimulants of two types (methylphenidate and amphetamines), ${ }^{22}$ atomoxetine, ${ }^{23}$ and extended-release versions of $\alpha_{2}$-adrenergic agonists. ${ }^{24-29}$ Empirically supported but off-label ADHD treatments include bupropion, tricyclic antidepressants, and traditional $\alpha_{2}$-adrenergic agonists. ${ }^{16}$ Detailed information on medication dose forms, typical starting and recommended maximum doses, and side effect-monitoring strategies are provided in the American Academy of Child and Adolescent Psychiatry ADHD practice parameters. ${ }^{16}$ Based on the clear association between exposure to ADHD medications and growth, height and weight should be regularly monitored. ${ }^{16}$ Aggression in the context of ADHD is a common problem, and may trigger atypical antipsychotic use for patients with ADHD. ${ }^{30}$ In view of the potential severe side effects of antipsychotic medications, it is essential to treat the underlying ADHD symptoms sufficiently through stimulants that can exert substantial antiaggression effects ${ }^{31}$ and with behavior interventions before considering other pharmacological options. Compared to older children, preschoolers appear more prone to 
medication side effects, and evidence of medication efficacy is less robust. Therefore, intensive behavioral therapies using empirically supported interventions are essential before considering careful trials of methylphenidate regimens ${ }^{32}$ The number of adolescents receiving ADHD treatment has been increasing, ${ }^{33}$ even though adolescents perceive pervasive barriers to help-seeking for mental disorders, most notably stigma, embarrassment, and poor mental health literacy. ${ }^{34}$

\section{Introduction to public stigma, courtesy stigma, and self- perception related to ADHD}

Stigma has been connoted as an internal mark and a "license to the social majority to perpetuate and escalate their judgmental attitudes and responses." ${ }^{35}$ Stigma surrounding mental illness and its treatment has been identified as a potent barrier to help-seeking, and youth with ADHD and their families are not immune from it. ${ }^{36}$ Successful management of ADHD requires awareness of the ubiquitous presence of stigma, its potential adverse consequences, and means to combat them. Stigma operates through social processes of comparison, identification, and devaluation, and the "mark" defining individuals as deviant, flawed, and undesirable can be physical, behavioral, biographical, or the result of group membership. ${ }^{35,37}$ The fundamental core of stigma may rest on the simple notion of individual differences. ${ }^{38}$ People are naturally inclined to notice disparities between themselves and others, and biases may result when these differences are not understood. Stigma has been conceptualized on different levels, including public, courtesy, and self stigma. Public stigma is often manifested in the forms of prejudice, stereotypes, and discrimination. The effects of stigma are not confined to the targeted individual, but also impact the families and friends of the stigmatized individual, who may in turn experience courtesy stigma resulting from an affiliation with the stigmatized person. ${ }^{38}$ Self-stigma may result when the stigmatized individual begins to accept the beliefs that others hold. ${ }^{39}$

Stigmatization associated with ADHD has been the subject of several recent pertinent reviews. One addressed the recent empirical literature from a developmental perspective, considering the age of the target and the perceiver of stigmatizing attitudes towards ADHD. ${ }^{40}$ Based on reviews of nationally representative data sets, surveys, experimental studies, and qualitative research, the author concluded that individuals exhibiting ADHD symptoms face substantial stigmatization, irrespective of their age, and that negative perceptions towards persons with ADHD are documented in children as well as adults. ${ }^{40}$ Similar findings are reported in a review of empirical literature addressing the main facets of stigma, (public, courtesy, self), and also exploring the influence of stigma on teachers' or university instructors' attitudes towards students with ADHD. ${ }^{41}$ The authors suggest that public uncertainty about the reliability and validity of an ADHD diagnosis, combined with skepticism towards the use of ADHD medications, enhance the stigma for this disorder, and caution that unaddressed stigma represents a risk factor with negative implications for treatment access, adherence, and outcomes. ${ }^{41}$

\section{Stigma measurement}

Over the past 10 years, a substantial increase in research on general mental illness-related stigma has occurred, resulting in newly developed measurement tools for stigma in its various forms ${ }^{42}$ Having these measurement tools is essential to evaluate impacts of emerging antistigma programs..$^{43}$ However, despite the high prevalence of ADHD in many countries $^{44}$ and the significance of stigma in the lives of those affected, limited psychometric research addressing ADHD stigma measurement is available. There are two studies reporting on a specific stigma tool: the ADHD stigma questionnaire (ASQ), and two studies reporting on ADHD treatment-attitude questionnaire development, which included stigma subscales as components of a broader tool (see Table 1). As part of a longitudinal observational study of help-seeking for ADHD, ${ }^{45}$ Bussing et al developed the ASQ by adapting an existing HIV stigma scale ${ }^{46}$ and documented acceptable psychometric performance of the ASQ in large community samples. ${ }^{47,48}$ Psychometric studies with adolescents established reliability, validated an overall stigma summary score, and demonstrated three subscales: disclosure concerns, negative self-image, and concern with public attitudes. ${ }^{48}$ Further study confirmed the ASQ's appropriateness for use with teachers. ${ }^{47}$ Ferrin et al developed a 33-item questionnaire on attitudes towards treatment for ADHD, and while this instrument does not directly target stigma measurement, parental responses identified a threeitem social stigma subscale in exploratory factor analysis. ${ }^{49}$ The authors caution that social stigma is too complex a construct to be fully covered in their treatment-attitudes questionnaire and suggest that social stigma perceptions deserve separate evaluation (see page 396). ${ }^{49}$ Pursuing similar goals as Ferrin et al, Harpur et al developed the Southampton ADHD medications behavior and attitude scale for parents (27 items, including four items each on parent and child stigma) and children (16 items, including four items 
Table I Attention deficit/hyperactivity disorder (ADHD) stigma measurement

\begin{tabular}{|c|c|c|c|}
\hline Study & Participants & Design & Findings \\
\hline Kellison et $\mathrm{al}^{48}$ & $\begin{array}{l}30 \text { I children and adolescents } \\
\text { (II-19 years) were recruited } \\
\text { from a North Florida school } \\
\text { district. }\end{array}$ & $\begin{array}{l}\text { The 26-item ADHD stigma questionnaire } \\
\text { (ASQ) was adapted from the HIV stigma } \\
\text { scale. Confirmatory factor analysis, internal } \\
\text { consistency reliability, test-retest reliability, } \\
\text { and construct validity were established. }\end{array}$ & $\begin{array}{l}\text { Among adolescents, the ASQ demonstrated } \\
\text { adequate reliability and validity and a three- } \\
\text { factor structure, with subscales of disclosure } \\
\text { concerns, negative self-image, and concern } \\
\text { with public attitudes. }\end{array}$ \\
\hline Bell et $\mathrm{al}^{47}$ & $\begin{array}{l}268 \text { teachers (mean age } \\
42.3 \text { years), including } 53 \text { with } \\
\text { special education certificate, } \\
\text { were recruited from a North } \\
\text { Florida school district. }\end{array}$ & $\begin{array}{l}\text { The study established internal consistency } \\
\text { and factor structure of the 26-item ADHD } \\
\text { stigma questionnaire (ASQ) for teachers. }\end{array}$ & $\begin{array}{l}\text { Among public school teachers, the ASQ } \\
\text { demonstrated adequate reliability and a } \\
\text { three-factor structure, with subscales of } \\
\text { disclosure concerns, negative self-image, } \\
\text { and concern with public attitudes. }\end{array}$ \\
\hline Ferrin et $\mathrm{al}^{49}$ & $\begin{array}{l}\text { I } 20 \text { adolescents (mean age } \\
14.7 \text { years) and their parents } \\
\text { were recruited from three } \\
\text { different child and adolescent } \\
\text { mental health clinics. }\end{array}$ & $\begin{array}{l}\text { The questionnaire on attitudes towards } \\
\text { treatment for ADHD (QATT) was } \\
\text { developed using a multistage process. } \\
\text { Exploratory factor analysis of the initial } \\
33 \text { items was performed. }\end{array}$ & $\begin{array}{l}\text { The adolescent version showed three } \\
\text { main dimensions (preoccupation, insight, } \\
\text { and self-concept). The parent version } \\
\text { showed six main dimensions (child's } \\
\text { personal attitudes, worries, social stigma, } \\
\text { insight, future side effects, and knowledge). }\end{array}$ \\
\hline Harpur et $\mathrm{al}^{50}$ & $\begin{array}{l}365 \text { parents and } 123 \text { children } \\
\text { (5-I8 years) were recruited } \\
\text { from UK clinics, US clinics, } \\
\text { ADHD parent-support groups, } \\
\text { and the Internet. }\end{array}$ & $\begin{array}{l}\text { The Southampton ADHD medication } \\
\text { behavior and attitude (SAMBA) scale } \\
\text { was developed. Exploratory factor } \\
\text { analysis was conducted for both parent } \\
\text { and child versions of SAMBA. }\end{array}$ & $\begin{array}{l}\text { Seven components emerged in the parent } \\
\text { questionnaire (benefits, costs, child stigma, } \\
\text { parental stigma, resistance, flexibility in } \\
\text { using medication, and inconsistency in using } \\
\text { medication), four in the child questionnaire } \\
\text { (benefits, costs, stigma, and resistance). }\end{array}$ \\
\hline
\end{tabular}

on child stigma). ${ }^{50}$ Among child respondents, child stigma emerged as the first factor in exploratory factor analysis (items addressing being made fun of for taking ADHD pills, feeling different from other children, being thought of as crazy, not feeling wanted as a friend) and explained $27 \%$ of the variance, whereas among parent respondents, child stigma emerged as the fifth factor, explaining $6 \%$ of variance, and parent stigma as the sixth factor, explaining $5 \%$ of variance. The authors comment on the robust component structure of the scale, but caution that further research is required to establish key psychometric features, including test-retest reliability and criterion validity (see page 467). ${ }^{50}$ Other measurement approaches to public stigma perception have utilized vignettes depicting persons with symptoms of various mental or physical disorders, combined with assessment of stigmatizing beliefs (prejudice, eg, perceived danger to self or others) and of stigmatizing actions (discrimination, eg, social distance, social regulation). ${ }^{51-56}$ For a current relevant detailed example of this approach, please see the description of the etiology and effects of the stigma model used for the National Stigma Study - Children (see page 52). ${ }^{53}$

\section{Public stigma}

Public stigma is often manifested in the forms of prejudice (eg, expectation of poor parenting practices or low effort/ laziness of child) and discrimination (eg, exclusion from social or recreational activities). Several recent studies have focused on public stigma perceptions related to ADHD from the perspective of youth and adults, utilizing qualitative, quantitative, or mixed-methods approaches (see Table 2 for summary).

Youth public stigma perspectives were assessed in one mixed-methods study and in four quantitative studies using vignettes. ${ }^{51,52,54,57}$ Bussing et al used a mixedmethods approach combining vignette responses and open-ended answers to study ADHD treatment willingness and perceptions of undesirable treatment side effects among four stakeholder groups for ADHD treatment of adolescents, namely 148 youth, 161 caregivers, 132 healthcare providers, and 122 teachers. ${ }^{57}$ Stigma associated with medication and behavioral therapies emerged as a significant treatment barrier in the qualitative analysis. The study also demonstrated that adolescents were significantly less willing than adults to consider medication or psychosocial treatments for ADHD. ${ }^{57}$

One vignette study sought to explore the impact of diagnostic/psychiatric labeling on the attitudes and behavioral intentions of school-age children towards a hypothetical peer presenting with ADHD symptoms. ${ }^{52}$ Law et al recruited 120 children from schools in the UK and found that the majority of participants held predominantly negative attitudes towards the vignette child with ADHD symptoms, with no additional effect of diagnostic/psychiatric labeling on children's attitudes and social behavioral intentions. ${ }^{52}$ 
Table 2 Public stigma

\begin{tabular}{l}
\hline Study Participants \\
\hline Youth public stigma perceptions \\
$\begin{array}{l}\text { Bussing } \\
\text { et }\left.\right|^{57}\end{array}$
\end{tabular}

et $\mathrm{al}^{57}$

Law et $\mathrm{a}^{52} \quad 120$ children $(\mathrm{I} \mid-12$ years) were recruited from three schools within the West Midlands region of the UK.

O'Driscoll 203 children (10-II years) and

et $\mathrm{al}^{54} \quad 182$ adolescents ( $15-16$ years) were recruited from public school in Ireland.

$\begin{array}{ll}\text { Coleman } & 1091 \text { youth (8-18 years) were } \\ \text { et } \mathrm{al}^{51} & \text { recruited for an online survey, } \\ & \text { with respondents approximating } \\ & \text { US census demographic targets. }\end{array}$

Walker $\quad 1318$ youth (8-18 years) were et $\mathrm{al}^{56} \quad$ recruited for an online survey, with respondents approximating US census demographic targets.

Adult public stigma perceptions

Arcia et $\mathrm{al}^{58} \quad 62$ Latina mothers of Cuban (63\%), Dominican (18\%), and Puerto Rican (19\%) descent who sought help for child.

Bussing $\quad 16 \mathrm{I}$ parents, 132 health professionals, et $\mathrm{al}^{57} \quad$ and 122 teachers.

Charach $\quad 17$ fathers and mothers of stimulantet a $^{59} \quad$ treated children with ADHD, ages $7-14$ years.
Design

Mixed methods. Vignette study using age and sex-matched peers with ADHD symptoms to assess treatment willingness, with grounded-theory analysis of openended responses about undesirable treatment effects.

Vignette study. Vignette I described symptoms of ADHD, vignette 2 stated "child has attention deficit hyperactivity," and vignette 3 also used the term “disorder.” Dependent variables were responses on a 34-item adjective checklist, and on the 24-item shared activities questionnaire.

Vignette study. Participants were randomly assigned to vignettes depicting an ageand sex-matched peer with ADHD or depression, and one with "normal issues." Dependent variables were explicit and implicit cognitions, including stereotyping, prejudice, and discrimination.

Vignette study, with respondents randomly assigned to one of three survey versions depicting child with ADHD, depression, or asthma.

Asthma was used as a control condition. Dependent variables were causal attributions and social distance; correlations were examined.

Vignette study, with respondents randomly assigned to one of three survey versions depicting child with ADHD, depression, or asthma. Asthma was used as a control condition.

Dependent variables were preferences for social distance, positive and negative attributions, and own family's attitude about a child with the target condition.

Mixed methods; telephone and personal interviews, with questionnaires and open-ended inquiry. Verbatim transcription and targeted analysis.

Mixed methods. Vignette study using adolescent boy or girl with ADHD symptoms to assess treatment willingness, with grounded-theory analysis of open-ended responses about undesirable treatment effects. Focus-group interviews, verbatim transcription, and phenomenologyinformed analysis.

\section{Findings}

Stigma emerged as important specific undesired effect of medications (particularly short-acting medications requiring school dosing) and of counseling therapy (public knowledge of receipt of counseling for ADHD was seen as very undesirable). There was no additional effect of diagnostic labeling on children's attitudes and social behavioral intentions. The four most frequently ascribed negative adjectives were "careless," "lonely," “crazy,” and "stupid.”

ADHD was more explicitly stigmatized than depression. Compared with younger children, adolescents were more prejudiced towards both disorders, especially ADHD. Peers with ADHD were viewed as more responsible for their condition compared with depressed peers.

Attributions to low child effort, parenting, and substance abuse represented a blaming view of mental health disorders among youth respondents. Stigmatizing views were strongest for depression and modest for ADHD.

Depression and ADHD elicited more stigmatization than asthma, especially expectations of antisocial behavior or violence. Family attitudes items indicated that respondents' families viewed depression more negatively than ADHD.

Most mothers did not administer medication consistently, and mothers had to negotiate deterring influences from family and friends who viewed it as stigmatizing. Stigma associated with medication and behavioral therapies emerged as a significant treatment barrier in the qualitative analysis.

Acceptance of ADHD and treatment need is a lengthy process, accompanied by confusion, self-doubt, and conflicting feedback from others. Stigmatization concerns and child's dislike of pills contribute to medication termination. 
Table 2 (Continued)

\begin{tabular}{|c|c|c|}
\hline Study & Participants & Design \\
\hline $\begin{array}{l}\text { DosReis } \\
\text { et } \mathrm{al}^{60}\end{array}$ & $\begin{array}{l}48 \text { caregivers of a child with ADHD, } \\
\text { recruited from primary care clinics, } \\
\text { developmental and behavioral } \\
\text { pediatric clinics, and specialty } \\
\text { mental health outpatient clinics. }\end{array}$ & $\begin{array}{l}\text { Individual interviews; grounded- } \\
\text { theory methods used to explore } \\
\text { parents' experiences with stigma } \\
\text { and to identify stigma patterns. }\end{array}$ \\
\hline $\begin{array}{l}\text { Fernandez } \\
\text { and } \text { Arcia }^{61}\end{array}$ & $\begin{array}{l}62 \text { Latina mothers of Cuban (63\%), } \\
\text { Dominican (18\%), and Puerto } \\
\text { Rican (19\%) descent who sought } \\
\text { help for child. }\end{array}$ & $\begin{array}{l}\text { Mixed methods; telephone and personal } \\
\text { interviews, with questionnaires and open- } \\
\text { ended inquiry. Verbatim transcription and } \\
\text { targeted analysis. }\end{array}$ \\
\hline $\begin{array}{l}\text { Olaniyan } \\
\text { et } a^{62}\end{array}$ & $\begin{array}{l}3 \text { I African-American adult } \\
\text { caregivers of children under } \\
\text { I } 7 \text { years; three had a child with } \\
\text { ADHD. }\end{array}$ & $\begin{array}{l}\text { Focus group interviews with five to seven } \\
\text { African-American parents per group; } \\
\text { verbatim transcription. Coding for } \\
\text { recurring themes, thematic analysis. }\end{array}$ \\
\hline
\end{tabular}

Martin et al ${ }^{53} \quad$ Nationally representative sample of I 393 adults, part of 2002 General Social Survey: National Stigma Study - Children (NSS-C).

Pescosolido et $\mathrm{al}^{55}$

Nationally representative sample of 1393 adults, part of 2002 General Social Survey: National Stigma Study - Children (NSS-C).

Pescosolido et al ${ }^{63}$
Nationally representative sample of I I 52 adults, part of 2002 General Social Survey: National Stigma Study - Children (NSS-C), with complete data on coercion questions.
Vignette study. Respondents were randomly assigned to vignettes depicting ADHD, depression, asthma, or normal troubles. The dependent variable was preferences for social distance from the vignette child, indexed by four responses (moving next door, own child making friends, socializing with vignette child's family, having child in their child's classroom).

Vignette study. Respondents were randomly assigned to vignettes depicting symptoms of ADHD, depression, asthma, or normal troubles. The vignettes did not contain categorization or problem labels. Dependent variables were recognition, labeling, and treatment recommendations. Vignette study. Respondents were randomly assigned to vignettes depicting ADHD, depression, asthma, or normal troubles. Dependent variables were respondents' perceptions of vignette child's likely danger to self or others, and whether parents of children like the vignette child should be forced by law to obtain various types of treatment (outpatient, medication, and inpatient).

\section{Findings}

Public stigma perceptions emerged in several thematic constructs: concerns with labeling, perceptions of a dismissive society, influence of negative public views, and exposure to negative media. Mothers reported experiencing stigma (39\%) from family, social networks, and schools.

Views of ADHD clustered around three issues: what a diagnosis means, the stigma associated with the diagnosis, and the medicalization of behavior problems. Concerns were expressed that an ADHD label could damage a child for the rest of their life. An ADHD label was also seen as reaction by school systems unresponsive to the needs of African-American children. Preferences for social distance were two to three times higher for ADHD (20\%) and depression (19\%) than asthma (6\%) and "normal troubles" (9\%). Higher preferences for social distance emerged for adolescents and those whose problems were perceived to be caused by lack of discipline or bad character.

Less than half of respondents could identify ADHD (42\%), and respondents were less likely to see ADHD as a serious mental illness (46\%) than depression (69\%). Nearly one in five who recognized ADHD rejected the mental illness label.

More respondents saw the child with ADHD (33\%) or depression (81\%) than children with asthma (15\%) or normal troubles (I3\%) as likely dangerous towards self or others. Respondents were more likely to endorse coerced treatment for children with depression (35\%) or asthma (42\%). For $A D H D$, few respondents were willing to use legal means to force the child with ADHD to receive outpatient (I7\%), medication (I2\%), or inpatient treatment (II\%).

Abbreviation: ADHD, attention deficit/hyperactivity disorder.

The remaining vignette studies included comparison conditions of depression, asthma, or "normal" troubles. A study by O'Driscoll et al assessed explicit and implicit stigma perceptions of 203 children and 182 adolescents who were randomly assigned to an age- and sex-matched vignette depicting a peer with ADHD, depression, or "normal issues." ${ }^{54}$ Questionnaire data showed more stigma and prejudice towards the peer with ADHD than the peer with depression, except for perceived danger and fear, whereas the implicit association test suggested some opposite findings. Overall, adolescents expressed more prejudice towards both disorders than younger children. The authors highlighted the importance of gathering both explicit and implicit stigma measures to develop a better understanding 
of youth stigma perceptions. ${ }^{54}$ Studies by Coleman et $\mathrm{al}^{51}$ and Walker et $\mathrm{al}^{56}$ were based on an online youth survey that assigned participants randomly to one of three vignettes depicting a child with depression, ADHD, or asthma. Walker et al reported on positive and negative attributions, social distance (willingness to have contact or engage with someone, with more desire for social distance indicating more stigma), and family attitudes towards a child with the vignette characteristics. ${ }^{56}$ Respondents made more negative attributions about peers with mental disorders than asthma, particularly expectations of antisocial behavior or violence, expressed more desire for social distance, and perceived more negative family attitudes towards peers with mental disorders than asthma. ${ }^{56}$ Coleman et al examined causal attributions and their correlation with social distance. Findings indicated that holding a belief that parenting, substance abuse, and low effort caused the condition were all strongly intercorrelated and moderately correlated with social distance. Furthermore, ADHD was modestly and depression strongly associated with stigmatizing beliefs. ${ }^{51}$ Findings from this online survey illustrated that ADHD and depression elicited more public stigma perceptions among youth than asthma, especially expectations of antisocial behavior or violence, and that a significant number of youth may hold a blaming view of mental health disorders. Overall, all these quantitative studies demonstrate that children and adolescents with ADHD continue to face a significant amount of stigma from their peers.

Adults' perceptions of public stigma were addressed in six qualitative/mixed-methods studies ${ }^{57-62}$ and three quantitative studies. ${ }^{53,55,63}$ The six qualitative/mixed-methods studies were conducted by various independent research groups focused on caregivers' public stigma experiences, whereas all quantitative studies originated from the 2002 General Social Survey, which contained a nationally representative sample of adults who completed the National Stigma Study Children (NSS-C). ${ }^{64}$ The qualitative/mixed-methods studies utilized individual and focus-group interviews of caregivers (mostly mothers) of youth with ADHD, and conducted analyses of the verbatim transcripts either to describe themes or develop grounded theory. Across studies, caregivers identified public stigma as a highly prevalent experience in their daily lives, originating from family members, friends, other network sources, and from school and health-care encounters. ${ }^{58,60,61}$ Public stigma was prompted by the child's behavior as well as by various treatments intended to help the disorder, and stigma was seen as a reason not to initiate or to stop treatment. ${ }^{57-59}$ Public stigma contributed to the fear of producing lifelong damage by having a child "labeled" with ADHD. ${ }^{62}$

Caregivers' perceptions of high prevalence of public stigma surrounding ADHD were confirmed in the NSS-C studies. ${ }^{53,55,63}$ The NSS-C study used a vignette approach in which participants were randomly assigned to vignettes depicting ADHD, depression, asthma, or "normal troubles." Pescosolido et al assessed recognition, labeling, and treatment recommendations for the four vignette types, and reported significant lack of understanding of ADHD. Notably, less than half of the respondents were able to identify ADHD, respondents were less likely to see ADHD as a serious mental illness than depression, and nearly one in five respondents who had recognized ADHD rejected ADHD as a mental illness altogether. ${ }^{55}$ Walker et al found higher stigma in the form of preference for social distance for ADHD and depression compared with asthma and "normal troubles. ${ }^{56} \mathrm{NSS}-\mathrm{C}$ respondents also expressed that children with ADHD or depression were more likely to be viewed as a danger to self or others than the comparison peers with asthma or "normal troubles," but fewer respondents were willing to use legal means to force outpatient treatment, medications, or inpatient treatments for children with ADHD than for children with depression, consistent with the perception that it is not a legitimate mental illness. ${ }^{63}$

Taken together, youth and adults affected by ADHD indicate that they experience high levels of public stigma, and these reports are validated by quantitative studies with representative samples that document considerable explicit and implicit stigmatization of ADHD.

\section{Courtesy stigma}

Not only is the person with a stigmatizing disorder affected, but his/her family members and other affiliated individuals also experience the manifestation of stigmatizing identity marks. ${ }^{35,38}$ Even though the entire family is influenced by courtesy stigma, mothers often carry the main responsibilities of nurturing a child with ADHD, and thus are most strongly affected by courtesy stigma. Implications of courtesy stigma in mothers' everyday lives are further perpetuated by popular discourses that portray ADHD as an ambiguous diagnosis, associated with controversies and doubts. ${ }^{65}$ This popular discourse leaves mothers more vulnerable to stigma. Sometimes stigma creates mother-blame related to the possibility of "being viewed as a bad mother" raising a "less perfect child." "3,66,67 This perception is especially reinforced in situations in which individuals believe that ADHD is not a legitimate diagnosis, but rather a result of poor parenting. 
Several recent studies have addressed courtesy stigma for caregivers of children with ADHD, including four based on qualitative and one on quantitative methods (see Table 3). ${ }^{60,61,68-70}$

Qualitative research methods addressing courtesy stigma included in-depth individual semistructured interviews and focus groups conducted with diverse samples, including African-American caregivers, ${ }^{60}$ Latina mothers of Cuban, Dominican, and Puerto Rican descent, ${ }^{61}$ and of Mexicanorigin Latino families. ${ }^{70}$ DosReis reports that most caregivers of young children with an initial diagnosis of ADHD reported stigmatizing experiences. Nearly half of her sample felt generally socially isolated and rejected as a result of their child's ADHD, and nearly a quarter also perceived that healthcare professionals and school personnel were unsupportive and dismissive of caregivers' concerns. ${ }^{60}$ Especially for younger children with ADHD, these professionals may play important roles in caregivers' social support networks, ${ }^{71}$ but may not always be aware of their importance to parental needs for social validation and support. Perry et al conducted

Table 3 Courtesy stigma of caregivers for youth with ADHD

\begin{tabular}{|c|c|c|c|}
\hline Study & Participants & Design & Findings \\
\hline DosReis et $\mathrm{al}^{60}$ & $\begin{array}{l}\text { Adults from primary care } \\
\text { clinics, developmental and } \\
\text { behavioral pediatric clinics, } \\
\text { and specialty mental health } \\
\text { outpatient clinics with children } \\
\text { newly diagnosed with ADHD. }\end{array}$ & $\begin{array}{l}\text { Grounded-theory methods used to } \\
\text { explore parents' experiences with } \\
\text { stigma. A coding manual was } \\
\text { developed to identify stigma patterns. }\end{array}$ & $\begin{array}{l}\text { Perceptions of courtesy stigma emerged } \\
\text { as feelings of social isolation and rejection, } \\
\text { and of being dismissed by society. }\end{array}$ \\
\hline Perry et $\mathrm{al}^{70}$ & $\begin{array}{l}27 \text { family members of children } \\
\text { with ADHD ( } 20 \text { mothers, } \\
\text { six fathers, one grandmother) } \\
\text { of } 24 \text { Latino families (mostly } \\
\text { Mexican) who were recent } \\
\text { immigrants. }\end{array}$ & $\begin{array}{l}\text { Semistructured conversational } \\
\text { interviews by bicultural interviewers; } \\
\text { verbatim transcription and translation } \\
\text { into English for } 16 \text { Spanish interviews; } \\
\text { grounded-theory analysis. }\end{array}$ & $\begin{array}{l}\text { Latino parents reported feeling extremely } \\
\text { stigmatized by child's disruptive behavior } \\
\text { because "manners matter" in their culture } \\
\text { and parents are expected to handle children } \\
\text { who do not show "good behavior." As parents } \\
\text { learned about biomedical explanations and } \\
\text { treatment, they felt less shame; many did } \\
\text { not see biomedical interventions as sufficient } \\
\text { to deal with the myriad behavioral concerns } \\
\text { that ADHD presented and sought counseling. }\end{array}$ \\
\hline $\begin{array}{l}\text { Fernandez and } \\
\text { Arcia }^{61}\end{array}$ & $\begin{array}{l}62 \text { Latina mothers of } \\
\text { Cuban }(63 \%) \text {, Dominican (18\%), } \\
\text { and Puerto Rican (19\%) descent } \\
\text { who sought help for child. }\end{array}$ & $\begin{array}{l}\text { Mixed methods; telephone and } \\
\text { personal interviews, with } \\
\text { questionnaires and open-ended } \\
\text { inquiry. Verbatim transcription } \\
\text { and targeted analysis. }\end{array}$ & $\begin{array}{l}\text { Mothers reported self-blame (42\%), which } \\
\text { was associated with lower education levels } \\
\text { and child-impairment ratings. Stigma sources } \\
\text { were family, social networks, schools, and } \\
\text { mothers' internal schema; stigma responses } \\
\text { included isolation, self-blame, blaming others, } \\
\text { and stigma rejection. }\end{array}$ \\
\hline $\begin{array}{l}\text { Koro-Ljungberg } \\
\text { and Bussing }\end{array}$ & $\begin{array}{l}30 \text { parents of youth diagnosed } \\
\text { with childhood ADHD. }\end{array}$ & $\begin{array}{l}\text { Two focus groups with mothers } \\
\text { and one with fathers; verbatim } \\
\text { transcription, grounded-theory } \\
\text { analysis, with member-checking as } \\
\text { part of quality control. }\end{array}$ & $\begin{array}{l}\text { Parents experience courtesy stigma positioned } \\
\text { in the parent-child dyadic relationship and } \\
\text { must manage courtesy stigma in various } \\
\text { contexts, including immediate family, social } \\
\text { network/community, schools, and health care. } \\
\text { Some contextual interactions are required } \\
\text { (eg, family members, school), whereas others } \\
\text { can be avoided (health care, community, social } \\
\text { network) if they worsen stigma experiences. }\end{array}$ \\
\hline Norvilitis et $\mathrm{al}^{69}$ & $\begin{array}{l}51 \text { mothers, } 23 \text { of children } \\
\text { with ADHD and } 28 \text { of children } \\
\text { without ADHD. }\end{array}$ & $\begin{array}{l}\text { Mothers completed a twelve-item } \\
\text { questionnaire about their own } \\
\text { ADHD attitudes; mothers of children } \\
\text { with ADHD also completed the } \\
\text { questionnaire, answering how they } \\
\text { thought parents of unaffected children } \\
\text { would answer. The dependent variable } \\
\text { was a composite discrepancy between } \\
\text { self-reported and perceived attitudes. } \\
\text { Several measures assessed stress and } \\
\text { social support. }\end{array}$ & $\begin{array}{l}\text { Mothers of children with ADHD expected } \\
\text { mothers of unaffected children to have } \\
\text { harsher views of the disorder than they } \\
\text { actually expressed. Mothers of ADHD } \\
\text { children reported more frequent criticism } \\
\text { of their parenting styles from those close } \\
\text { to them than mothers of non-ADHD children. }\end{array}$ \\
\hline
\end{tabular}

Abbreviation: ADHD, attention deficit/hyperactivity disorder. 
interviews with 24 Latino families who had a child diagnosed with ADHD. ${ }^{70}$ Parents reported feeling intensely stigmatized by their child's disruptive behavior, because "manners matter" in their culture and parents are blamed for children who do not show "good behavior." Ways of dealing with courtesy stigma included learning about biomedical explanations of ADHD behavior so parents could feel less shame and become more efficient in seeking treatment. ${ }^{70}$ High levels of courtesy-stigma experiences were also reported among Latina mothers who had sought help for their child, ${ }^{61}$ whose stigma experiences derived from external (family, friends, acquaintances, schools) and internal sources (internal schema and self-blame). KoroLjungberg and Bussing reported similar findings among parents of adolescents with ADHD ${ }^{68}$ Their conceptual model positions the parental experience of courtesy in the dyadic relationship with the child, with the requirements to manage courtesy stigma in various social contexts, some of which are unavoidable (like immediate family or school), whereas others can be avoided to some degree (extended family, friends, community, health care). Their research documents that parental efforts to cope with courtesy stigma may at times backfire and produce undesirable results; without considering courtesy stigma, treatment providers may be unable to establish effective treatment plans.

Only one study was able to be identified that sought to address courtesy stigma through quantitative research designs. Norvilitis et al conducted a study with 51 mothers, including 23 who had children with ADHD and 28 who had children without (unaffected mothers). ${ }^{69}$ The study used a newly developed and not yet validated courtesy stigma questionnaire comprised of twelve items tapping into reported or perceived attitudes towards ADHD (eg, most children with ADHD just need more discipline) and parents rated agreement on a scale from 1 (strongly agree) to 5 (strongly disagree). Mothers of children with ADHD completed the questionnaire twice, once representing their own attitudes, and the second time answering as they presumed most unaffected parents would answer, whereas unaffected mothers only selected their own responses. The researchers sought to analyze courtesy stigma by studying the discrepancies between affected and unaffected parents, as well as the discrepancies between the presumed and actual responses of unaffected parents. Mothers of the two groups did not differ significantly in their actual attitudes, but affected mothers expected more negative responses from unaffected mothers than were actually provided. In brief, the authors concluded that affected mothers' courtesystigma perceptions may "not be completely accurate." 69 However, even though the study's general research approach to courtesy stigma is innovative, conclusions are severely limited by the absence of psychometric reporting for the new instrument, the small convenience sample, and the

Table 4 Self stigma and self perceptions

\begin{tabular}{|c|c|c|c|}
\hline Study & Participants & Design & Findings \\
\hline $\begin{array}{l}\text { Koro-Ljungberg } \\
\text { et } \mathrm{al}^{72}\end{array}$ & $\begin{array}{l}\text { Four African-American } \\
\text { adolescents with ADHD. }\end{array}$ & $\begin{array}{l}\text { Three-month qualitative } \\
\text { experience sampling method } \\
\text { with verbatim transcription of } \\
\text { messages and narrative analysis } \\
\text { framed within context of } \\
\text { African-American rhetorical } \\
\text { tradition. }\end{array}$ & $\begin{array}{l}\text { Adolescent-constructed narratives about daily } \\
\text { lived experiences of ADHD differ markedly } \\
\text { from the terminology used by providers, } \\
\text { influenced by DSM-IV-based medical discourses } \\
\text { on ADHD. Adolescents selected discourse } \\
\text { features that support preferred identities and } \\
\text { avoided stigmatizing language, allowing them to } \\
\text { present in socially/culturally desirable positions. }\end{array}$ \\
\hline Singh et $\mathrm{al}^{73}$ & $\begin{array}{l}\text { I6 purposefully sampled youth } \\
\text { aged 9-I4 years with primary } \\
\text { ADHD diagnosis, on medication }\end{array}$ & $\begin{array}{l}\text { Focus groups and individual } \\
\text { interviews, using topic guide, } \\
\text { semistructured interview, and } \\
\text { vignette. Verbatim transcription } \\
\text { and thematic analysis. }\end{array}$ & $\begin{array}{l}\text { Majority of youth experienced bullying about } \\
\text { ADHD behavior and diagnosis, impacting } \\
\text { their self-confidence and self-esteem. Stigma } \\
\text { arising from medication was significantly less } \\
\text { frequently expressed than stigma from behavior } \\
\text { or diagnosis. Youth desired better public } \\
\text { understanding of ADHD, expecting it would } \\
\text { create empathy and relieve stigma. }\end{array}$ \\
\hline Waite and $\operatorname{Tran}^{74}$ & $\begin{array}{l}27 \text { postsecondary minority } \\
\text { students (eleven male and } \\
16 \text { female) with diagnosed ADHD } \\
\text { recruited through flyers from two } \\
\text { northeastern community colleges } \\
\text { and two research universities. }\end{array}$ & $\begin{array}{l}\text { In-depth interviews assessing } \\
\text { explanatory models; verbatim } \\
\text { transcription, content analysis. }\end{array}$ & $\begin{array}{l}\text { Family perceptions of stigma surrounding } \\
\text { ADHD and self-stigma contributed to feelings of } \\
\text { young adults' feelings of despair. ADHD stigma } \\
\text { was cited as a reason not to access supports or } \\
\text { services through student disability offices. }\end{array}$ \\
\hline
\end{tabular}

Abbreviations: ADHD, attention deficit/hyperactivity disorder; DSM, Diagnostic and Statistical Manual of Mental Disorders. 
fact that the unaffected mothers who responded to the study invitation may not resemble the persons encountered by affected mothers in their daily lives. In summary, even though multiple qualitative study results indicate that courtesy stigma is highly prevalent and an important consideration in establishing therapeutic relationships during ADHD treatment, prevalence has not been studied through quantitative research methods, and currently no validated instrument is available to measure courtesy stigma.

\section{Self-stigma and self-perception of youth with ADHD}

Very limited research has addressed self-stigma experiences of youth with ADHD. Only three qualitative studies could be identified that address this topic (see Table 4). ${ }^{72-74}$ The dearth of studies on self-stigma is in contrast to a larger literature on self-perceptions of youth with ADHD. Children with ADHD have been shown to exhibit self-perception bias, also previously referred to as positive illusory bias (PIB), resulting in positive reports of their own competence, despite significant functional problems in multiple domains, as measured through other sources. ${ }^{75} \mathrm{~A}$ recent review of research on self-perception and PIB in ADHD supports the existence of inflated self-perceptions of self-competence in some children with ADHD, but cautions that the critical question of whether or not PIB is adaptive or maladaptive is still unanswered. ${ }^{75}$ This review does not try to relate PIB to stigma experiences or self-stigma associated with ADHD either. The qualitative research on self-stigma includes a longitudinal qualitative experience sampling study of four African-American adolescents with ADHD, where verbatim transcriptions of communications were analyzed using narrative analysis in the context of African-American rhetorical tradition. In this research, adolescents could select their own discourses about their daily life experiences with ADHD. The adolescents selected discourse features that supported their preferred identities and avoided stigmatizing language, so that they could present themselves in socially/ culturally desirable positions. The two other qualitative studies utilized focus-group or in-depth interviews, where adolescents were asked to respond directly to questions about stigma experiences. In Singh's study of UK adolescents diagnosed with and treated for ADHD, the majority reported experiencing bullying about their ADHD behavior and diagnosis, and they related it to lowered self-confidence and self-esteem. ${ }^{73}$ Comparable findings of stigma experiences leading to self-stigma and associated feelings of despair were reported by Waite and Tran for postsecondary minority students with ADHD in the US. ${ }^{74}$ In summary, then, the area of self-stigma in youth with ADHD is seriously understudied, with some indication that affected adolescents experience lowered self-confidence in response to public stigma; these findings need to be integrated with reports of inflated selfperceptions and PIB in youth with ADHD.

\section{Patient considerations in labeling youth with ADHD, including stigmatizing experiences of child and parents}

Treatment providers whose initial evaluation confirms a diagnosis of ADHD need to be aware of the dynamics of public and courtesy stigma that are undisputedly associated with the disorder, because unaddressed stigma affects the therapeutic relationship, the family's ability to engage in treatment planning and ongoing management, and ultimately worsens the chances of optimal outcomes for the affected youth. As indicated in our review, there are limited validated stigma-assessment tools available for clinician use, and none lends itself to clinical application in a treatment encounter. For this reason, it is crucial that treatment providers talk with caregivers and youth about their experiences and stigma concerns to allow integration of stigma interventions into the overall psychoeducational intervention plan. At a societal level, stigma interventions include protest, education, and contact; ${ }^{43}$ at the individual level, families can benefit from similar personalized applications, eg, learning to protest explicitly if other family members act in a discriminatory fashion towards them or their child with ADHD, seeking and dispensing trustworthy education about ADHD, and cultivating contact with other families facing similar challenges through Children and Adults with Attention Deficit/Hyperactivity Disorder or the National Alliance on Mental Illness.

It is important to distinguish families' stigma-management efforts from general coping strategies prompted by a health condition. Coping is directed at the inherent effects of the condition (which would need to be dealt with even in the absence of stigma), whereas stigma management represents an extra layer of effort, directed at stereotyping and discrimination resulting from the condition. Parents of children with asthma, for example, have to develop comprehensive coping skills to minimize exposures to potentially triggering events, administer prescribed regimens, and respond to their child's breathing problems, ${ }^{76}$ but do not experience the high level of social stigma extended towards 
parents whose children have mental disorders, especially ADHD. ${ }^{53}$

\section{Conclusions and future perspectives}

Stigma experiences associated with ADHD are ubiquitous and potentially deleterious to good treatment and outcomes. Even though recent research has helped us to better understand stigma components associated with mental disorders, including ADHD, we still need better tools to assess, address, and prevent this unfortunate "mark." Numerous general antistigma programs have been developed and implemented internationally, ${ }^{77}$ but none has been specifically developed to combat ADHD stigma. As summarized in Corrigan and Shapiro, approaches to public stigma change have been divided into three paradigms - protest, education, and contact $^{43}$ - but insufficient guidance exists for treatment providers on how to combat stigma experienced by individual patients. Societal efforts to establish parity for mental disorders are one important contribution towards ending the unfair financial burden carried by those with mental disorders, including ADHD. Additional efforts are called for to advance stigma measurement, so we can document its presence and hopefully measure its decline. Most importantly, concerted efforts are needed to increase accurate information dissemination about mental disorders, including ADHD, to combat the roots feeding stigma, as eloquently expressed by Pescosolido et al, "unless systematically addressed, the public's lack of knowledge, skepticism, and misinformed beliefs signal continuing problems for providers, as well as for caregivers and children seeking treatment."55

\section{Disclosure}

The authors report no conflicts of interest in this work.

\section{References}

1. American Psychiatric Association. Diagnostic and Statistical Manual of Mental Disorders, 4th ed, text revision. Washington: American Psychiatric Association; 2000.

2. Centers for Disease Control and Prevention. Increasing prevalence of parent-reported attention-deficit/hyperactivity disorder among children United States, 2003 and 2007. MMWR Morb Mortal Wkly Rep. 2010;59(44):1439-1443.

3. Singh I. Doing their jobs: mothering with Ritalin in a culture of mother-blame. Soc Sci Med. 2004;59(6):1193-1205.

4. Castellanos FX, Proal E. Location, location, and thickness: volumetric neuroimaging of attention-deficit/hyperactivity disorder comes of age. J Am Acad Child Adolesc Psychiatry. 2009;48(10):979-981.

5. Faraone SV, Perlis RH, Doyle AE, et al. Molecular genetics of attention-deficit/hyperactivity disorder. Biol Psychiatry. 2005;57(11): 1313-1323.

6. Nigg JT. What Causes ADHD: Understanding What Goes Wrong and Why. New York: Guilford; 2006.

7. Willcutt EG, Doyle AE, Nigg JT, Faraone SV, Pennington BF. Validity of the executive function theory of attention-deficit/hyperactivity disorder: a meta-analytic review. Biol Psychiatry. 2005;57(11):1336-1346.
8. Lara C, Fayyad J, de Graaf R, et al. Childhood predictors of adult attention-deficit/hyperactivity disorder: results from the World Health Organization World Mental Health Survey Initiative. Biol Psychiatry. 2009;65(1):46-54.

9. Molina BS, Hinshaw SP, Swanson JM, et al. The MTA at 8 years: prospective follow-up of children treated for combined-type ADHD in a multisite study. J Am Acad Child Adolesc Psychiatry. 2009;48(5): 484-500.

10. Danckaerts M, Sonuga-Barke EJ, Banaschewski T, et al. The quality of life of children with attention deficit/hyperactivity disorder: a systematic review. Eur Child Adolesc Psychiatry. 2010;19(2):83-105.

11. Barry CL, Busch SH. Caring for children with mental disorders: do state parity laws increase access to treatment? J Ment Health Policy Econ. 2008;11(2):57-66.

12. Waite R, Ramsay JR. A model for parental ADHD: help-seeking and readiness to change. Issues Ment Health Nurs. 2010;31(12):793-803.

13. Wolraich M, Brown L, Brown RT, et al. ADHD: clinical practice guideline for the diagnosis, evaluation, and treatment of attentiondeficit/hyperactivity disorder in children and adolescents. Pediatrics. 2011;128(5):1007-1022.

14. Cohen MD. Educational rights of children and adolescents with attention-deficit/hyperactivity disorder. Adolesc Med State Art Rev. 2008;19(2):327-338, xi.

15. Pelham WE Jr, Fabiano GA. Evidence-based psychosocial treatments for attention-deficit/hyperactivity disorder. J Clin Child Adolesc Psychol. 2008;37(1):184-214.

16. Pliszka S. Practice parameter for the assessment and treatment of children and adolescents with attention-deficit/hyperactivity disorder. J Am Acad Child Adolesc Psychiatry. 2007;46(7):894-921.

17. American Academy of Child and Adolescent Psychiatry. Policy statement: family and youth participation in clinical decision-making 2009. Available from: http://aacap.org/cs/root/policy_statements/ family_and_youth_participation_in_clinical_decisionmaking. Accessed February 10, 2010.

18. Franklin SA, Walther MR, Woods DW. Behavioral interventions for tic disorders. Psychiatr Clin North Am. 2010;33(3):641-655.

19. Littell JH, Popa M, Forsythe B. Multisystemic therapy for social, emotional, and behavioral problems in youth aged 10-17. Cochrane Database Syst Rev. 2005;(4):CD004797.

20. Mancuso E, Faro A, Joshi G, Geller DA. Treatment of pediatric obsessivecompulsive disorder: a review. J Child Adolesc Psychopharmacol. 2010; 20(4):299-308.

21. Sonuga-Barke EJ, Brandeis D, Cortese S, et al. Nonpharmacological interventions for ADHD: systematic review and meta-analyses of randomized controlled trials of dietary and psychological treatments. Am J Psychiatry. 2013;170(3):275-289.

22. Arnold LE. Methylphenidate vs amphetamine: comparative review. J Atten Disord. 2000;3(4):200-211.

23. Garnock-Jones KP, Keating GM. Spotlight on atomoxetine in attentiondeficit hyperactivity disorder in children and adolescents. CNS Drugs. 2010;24(1):85-88.

24. Biederman J, Melmed RD, Patel A, McBurnett K, Donahue J, Lyne A. Long-term, open-label extension study of guanfacine extended release in children and adolescents with ADHD. CNS Spectr. 2008;13(12): 1047-1055.

25. Biederman J, Melmed RD, Patel A, et al. A randomized, double-blind, placebo-controlled study of guanfacine extended release in children and adolescents with attention-deficit/hyperactivity disorder. Pediatrics. 2008;121(1):e73-e84.

26. Sallee FR, Lyne A, Wigal T, McGough JJ. Long-term safety and efficacy of guanfacine extended release in children and adolescents with attention-deficit/hyperactivity disorder. J Child Adolesc Psychopharmacol. 2009;19(3):215-226.

27. Sallee FR, McGough J, Wigal T, Donahue J, Lyne A, Biederman J. Guanfacine extended release in children and adolescents with attentiondeficit/hyperactivity disorder: a placebo-controlled trial. J Am Acad Child Adolesc Psychiatry. 2009;48(2):155-165. 
28. Kollins SH, Jain R, Brams M, et al. Clonidine extended-release tablets as add-on therapy to psychostimulants in children and adolescents with ADHD. Pediatrics. 2011;127(6):e1406-e1413.

29. Jain R, Segal S, Kollins SH, Khayrallah M. Clonidine extendedrelease tablets for pediatric patients with attention-deficit/hyperactivity disorder. J Am Acad Child Adolesc Psychiatry. 2011;50(2):171-179.

30. Constantine RJ, Boaz T, Tandon R. Antipsychotic polypharmacy in the treatment of children and adolescents in the fee-for-service component of a large state Medicaid program. Clin Ther. 2010;32(5):949-959.

31. Pappadopulos E, Woolston S, Chait A, Perkins M, Connor DF, Jensen PS. Pharmacotherapy of aggression in children and adolescents: efficacy and effect size. J Can Acad Child Adolesc Psychiatry. 2006;15(1):27-39.

32. Murray DW. Treatment of preschoolers with attention-deficit/ hyperactivity disorder. Curr Psychiatry Rep. 2010;12(5):374-381.

33. Zuvekas SH, Vitiello B. Stimulant medication use in children: a 12-year perspective. Am J Psychiatry. 2012;169(2):160-166.

34. Gulliver A, Griffiths KM, Christensen H. Perceived barriers and facilitators to mental health help-seeking in young people: a systematic review. BMC Psychiatry. 2010;10:113.

35. Hinshaw SP. The Mark of Shame: Stigma of Mental Illness and an Agenda for Change. Oxford: Oxford University Press; 2007.

36. US Department of Health and Human Services. Mental Health: A Report to the Surgeon General. USDHHS; 1999.

37. Jones EE. Social Stigma: The Psychology of Marked Relationships. New York: WH Freeman; 1984

38. Goffman E. Stigma: Notes on the Management of Spoiled Identity. Englewood Cliffs (NJ): Prentice-Hall; 1963.

39. Corrigan PW. How stigma interferes with mental health care. Am Psychol. 2004;59(7):614-625.

40. Lebowitz MSL. Stigmatization of ADHD: a developmental review. J Attent Disord. Epub February 13, 2013.

41. Mueller AK, Fuermaier AB, Koerts J, Tucha L. Stigma in attention deficit hyperactivity disorder. Atten Defic Hyperact Disord. 2012; 4(3):101-114

42. Brohan E, Slade M, Clement S, Thornicroft G. Experiences of mental illness stigma, prejudice and discrimination: a review of measures. $B M C$ Health Serv Res. 2010;10:80.

43. Corrigan PW, Shapiro JR. Measuring the impact of programs that challenge the public stigma of mental illness. Clin Psychol Rev. 2010; 30(8):907-922.

44. Polanczyk G, de Lima MS, Horta BL, Biederman J, Rohde LA. The worldwide prevalence of ADHD: a systematic review and metaregression analysis. Am J Psychiatry. 2007;164(6):942-948.

45. Bussing R, Mason DM, Bell L, Porter P, Garvan C. Adolescent outcomes of childhood attention-deficit/hyperactivity disorder in a diverse community sample. J Am Acad Child Adolesc Psychiatry. 2010; 49(6):595-605.

46. Berger BE, Ferrans CE, Lashley FR. Measuring stigma in people with HIV: psychometric assessment of the HIV stigma scale. Res Nurs Health. 2001;24(6):518-529.

47. Bell L, Long S, Garvan C, Bussing R. The impact of teacher credentials on ADHD stigma perceptions. Psychol Sch. 2011;48(2):184-197.

48. Kellison I, Bussing R, Bell L, Garvan C. Assessment of stigma associated with attention-deficit hyperactivity disorder: psychometric evaluation of the ADHD stigma questionnaire. Psychiatry Res. 2010; 178(2):363-369.

49. Ferrin M, Ruiz-Veguilla M, Blanc-Betes M, et al. Evaluation of attitudes towards treatment in adolescents with attention deficit hyperactivity disorder (ADHD). Eur Child Adolesc Psychiatry. 2012;21(7): $387-401$.

50. Harpur RA, Thompson M, Daley D, Abikoff H, Sonuga-Barke EJ. The attention-deficit/hyperactivity disorder medication-related attitudes of patients and their parents. J Child Adolesc Psychopharmacol. 2008; 18(5):461-473.

51. Coleman D, Walker JS, Lee J, Friesen BJ, Squire PN. Children's beliefs about causes of childhood depression and ADHD: a study of stigmatization. Psychiatr Serv. 2009;60(7):950-957.
52. Law GU, Sinclair S, Fraser N. Children's attitudes and behavioural intentions towards a peer with symptoms of ADHD: does the addition of a diagnostic label make a difference? J Child Health Care. 2007;11(2): 98-111.

53. Martin JK, Pescosolido BA, Olafsdottir S, McLeod JD. The construction of fear: Americans' preferences for social distance from children and adolescents with mental health problems. J Health Soc Behav. 2007; 48(1):50-67.

54. O’Driscoll C, Heary C, Hennessy E, McKeague L. Explicit and implicit stigma towards peers with mental health problems in childhood and adolescence. J Child Psychol Psychiatry. 2012;53(10):1054-1062.

55. Pescosolido BA, Jensen PS, Martin JK, Perry BL, Olafsdottir S, Fettes D. Public knowledge and assessment of child mental health problems: findings from the National Stigma Study - Children. J Am Acad Child Adolesc Psychiatry. 2008;47(3):339-349.

56. Walker JS, Coleman D, Lee J, Squire PN, Friesen BJ. Children's stigmatization of childhood depression and ADHD: magnitude and demographic variation in a national sample. J Am Acad Child Adolesc Psychiatry. 2008;47(8):912-920.

57. Bussing R, Koro-Ljungberg M, Noguchi K, Mason D, Mayerson G, Garvan CW. Willingness to use ADHD treatments: a mixed methods study of perceptions by adolescents, parents, health professionals and teachers. Soc Sci Med. 2012;74(1):92-100.

58. Arcia E, Fernandez MC, Jaquez M. Latina mothers' stances on stimulant medication: complexity, conflict, and compromise. J Dev Behav Pediatr. 2004;25(5):311-317.

59. Charach A, Skyba A, Cook L, Antle BJ. Using stimulant medication for children with ADHD: what do parents say? A brief report. J Can Acad Child Adolesc Psychiatry. 2006;15(2):75-83.

60. DosReis S, Barksdale CL, Sherman A, Maloney K, Charach A. Stigmatizing experiences of parents of children with a new diagnosis of ADHD. Psychiatr Serv. 2010;61(8):811-816.

61. Fernández M, Arcia E. Disruptive behaviors and maternal responsibility: a complex portrait of stigma, self-blame, and other reactions. Hisp J Behav Sci. 2004;26(3):356-372.

62. Olaniyan $\mathrm{O}$, dosReis $\mathrm{S}$, Garriett $\mathrm{V}$, et al. Community perspectives of childhood behavioral problems and ADHD among African American parents. Ambul Pediatr. 2007;7(3):226-231.

63. Pescosolido BA, Fettes DL, Martin JK, Monahan J, McLeod JD. Perceived dangerousness of children with mental health problems and support for coerced treatment. Psychiatr Serv. 2007;58(5): 619-625.

64. Pescosolido BA. Culture, children, and mental health treatment: special section on the National Stigma Study - Children. Psychiatr Serv. 2007; 58(5):611-612.

65. Malacrida C. Motherhood, resistance, and attention deficit disorder: strategies and limits. Can Rev Sociol Anthropol. 2001;38(2): 141-165.

66. Blum L. Mother-blame in the Prozac nation: raising kids with invisible disabilities. Gend Soc. 2007;21(2):202-226.

67. Caplan P. Don't Blame Mother: Mending the Mother-Daughter Relationship. New York: Harper and Row; 1989.

68. Koro-Ljungberg M, Bussing R. The management of courtesy stigma in the lives of families with teenagers with ADHD. J Fam Issues. 2009; 30(9):1175-1200.

69. Norvilitis JM, Scime M, Lee JS. Courtesy stigma in mothers of children with attention-deficit/hyperactivity disorder: a preliminary investigation. JAtten Disord. 2002;6(2):61-68.

70. Perry CE, Hatton D, Kendall J. Latino parents' accounts of attention deficit hyperactivity disorder. J Transcult Nurs. 2005;16(4):312-321.

71. Bussing R, Zima BT, Gary FA, et al. Social networks, caregiver strain, and utilization of mental health services among elementary school students at high risk for ADHD. J Am Acad Child Adolesc Psychiatry. 2003;42(7):842-850.

72. Koro-Ljungberg M, Bussing R, Williamson P, Wilder J, Mills T. African-American teenagers' stories of attention deficit/hyperactivity disorder. J Child Fam Stud. 2008;17(4):467-485. 
73. Singh I, Kendall T, Taylor C, et al. Young people's experience of ADHD and stimulant medication: a qualitative study for the NICE Guideline. Child Adolesc Ment Health. 2010;15(4):186-192.

74. Waite R, Tran M. Explanatory models and help-seeking behavior for attention-deficit/hyperactivity disorder among a cohort of postsecondary students. Arch Psychiatr Nurs. 2010;24(4):247-259.

75. Owens JS, Goldfine ME, Evangelista NM, Hoza B, Kaiser NM. A critical review of self-perceptions and the positive illusory bias in children with ADHD. Clin Child Fam Psychol Rev. 2007;10(4):335-351.
76. Peterson-Sweeney K, McMullen A, Yoos HL, Kitzman H. Parental perceptions of their child's asthma: management and medication use. J Pediatr Health Care. 2003;17(3):118-125.

77. Beldie A, den Boer JA, Brain C, et al. Fighting stigma of mental illness in midsize European countries. Soc Psychiatry Psychiatr Epidemiol. 2012;47 Suppl 1:1-38.
Patient Intelligence

\section{Publish your work in this journal}

Patient Intelligence is an international, peer-reviewed, open access journal that characterizes and measures the central role of patient behavior and intention in optimizing healthcare management in all areas of disease and complaint types. An improved understanding of patient intelligence coupled with predictive analysis helps an organization contribute more effectively to achieving better outcomes

Submit your manuscript here: http://www.dovepress.com/patient-intelligence-journal

\section{Dovepress}

The journal is characterized by the rapid reporting of reviews, original research, methodologies, analytics, modeling, clinical studies and patient surveys across all disease areas. The manuscript management system is completely online and includes a very quick and fair peer-review system. Visit http://www.dovepress.com/ testimonials.php to read real quotes from published authors. 